University of Nebraska - Lincoln

DigitalCommons@University of Nebraska - Lincoln

Papers in Biotechnology

Chemical and Biomolecular Engineering

Research and Publications

$1-1-2005$

\title{
Preparation and evaluation of the electrospun chitosan/PEO fibers for potential applications in cartilage tissue engineering
}

\author{
Anuradha Subramanian \\ Department of chemical Engineering,University of Nebraska Lincoln., asubramanian2@unl.edu \\ David Vu \\ Department of Chemical and Biomolecular Engineering, University of Nebraska Lincoln, \\ dvu@engrs.unl.edu \\ Gustavo F. Larsen \\ University of Nebraska - Lincoln, glarsen1@unl.edu \\ Hsin Yli Lin \\ Department of Chemical and Biomolecular Engineering, University of Nebraska, Lincoln
}

Follow this and additional works at: https://digitalcommons.unl.edu/chemeng_biotechnology

Part of the Biochemical and Biomolecular Engineering Commons

Subramanian, Anuradha; Vu, David; Larsen, Gustavo F.; and Lin, Hsin Yli, "Preparation and evaluation of the electrospun chitosan/PEO fibers for potential applications in cartilage tissue engineering" (2005). Papers in Biotechnology. 29.

https://digitalcommons.unl.edu/chemeng_biotechnology/29

This Article is brought to you for free and open access by the Chemical and Biomolecular Engineering Research and Publications at DigitalCommons@University of Nebraska - Lincoln. It has been accepted for inclusion in Papers in Biotechnology by an authorized administrator of DigitalCommons@University of Nebraska - Lincoln. 


\section{INTRODUCTION}

The application of the principles of tissue engineering to cartilage repair was first proposed by Green in 1977 [1], who suggested the transplantation of chondrocytes cultured in an ex vivo environment into a cartilage defect. Clinical application of such an approach was attempted in 1985 and since then cartilage repair techniques that utilize cultured chondrocytes have attracted significant attention [2]. Recently,

cell-based repair approaches for replacement and regeneration of articular cartilage are being developed using various scaffold configurations and cell sources like chondrocytes and mesenchymal stem cells.

Tissue engineering of articular cartilage involves the isolation of articular chondrocytes or their precursor cells, followed by seeding onto a biocompatible matrix or scaffold, and further implantation into the defect or joint. In cell-based therapies to cartilage tissue engineering, the scaffold organization and architecture are equally important. Scaffolds based on natural and synthetic polymers have been evaluated in both in vitro and in vivo applications [3-13]. The studies have shown that these different biomaterials can support the formation of collagen and proteoglycan (PG)containing tissue.

An ideal cell-carrier substrate that mimics the naturally occurring environment in the articular cartilage matrix is desired. Articular cartilage has a hierarchical structure in itself and is also part of a diarthrodial joint which has a composite structure consisting of bone, articular cartilage, ligaments, tendons, muscle and the joint capsule. At a microstructural level (between $0.1 \mu \mathrm{m}$ and $100 \mu \mathrm{m}$ ), the articular cartilage is characterized by the hierarchical organization of the type-II collagen fibrils into 'zones' and the chondrocytes, the cell type that populate the matrix. These zones contain different collagen organization as well different amounts of type-II collagen [14]. The material properties of articular cartilage are as follows: a compressive equilibrium aggregate modulus of $0.5-1.2 \mathrm{MPa}$, a tensile equilibrium modulus of 15-40 MPa and a permeability of $(0.5-5) \times 10^{-15} \mathrm{~m}^{4} /(\mathrm{N} \mathrm{s})$.

In addition to natural cartilage explants, collagen based surfaces ranging from film coatings $[5,15]$, collagen gels $[8,16,17]$, collagen spheres [18], or spongelike scaffolds [19-21] have been employed in efforts to grow cartilage in vitro, as collagen has been shown to support proliferation of chondrocytes [22]. In addition to planar surfaces and sponge-like scaffolds, hydrogels have been prepared from alginates, fibrin glue and photo-cross-linkable poly(ethylene glycol) (PEG) $[23,24]$.

Recently, it has been proposed that scaffolds with nanoscale features can improve bone, vascular, bladder, cartilage, neural and other cell functions [25-29]. These structures are primarily composed of collagen, exhibiting fiber diameters that are one or more orders of magnitude smaller than the cell itself [30]. In this study we have used chitosan, which has been shown to support and promote chondrocyte attachment, to make scaffolds with oriented nano-/sub-micron fibers. Chitosan $(\beta$-(1-4)-2-amino-2-deoxy-D-glucose) a natural polyaminosaccharide derived from $\mathrm{N}$-deacetylation of chitin has shown to possess attractive biological and cell interactive properties [31-34]. Recently, chitosan and chitosan-analogs have also been shown to support the growth and continued function of chondrocytes $[27,31,35]$, making it especially suitable for development of a 'model system' for use in cartilage tissue engineering.

The technique of electrospinning offers an attractive alternative to achieve these small fiber diameters. The utilization of electrohydrodynamic (EHD) methods, specifically in the so-called electrospinning mode, for tissue scaffold design is be- 
ginning to be realized $[25,26,28,36]$. Recent work has resulted in the preparation of scaffolds from fibrinogen, collagen and poly-glycolic acid using the ES process [26, 28]. Shin et al. [37] have recently reported on actual tissue development over an electrospun nanofibrous scaffold. The authors employed fibrous scaffolds based on randomly oriented poly ( $\varepsilon$-caprolactone) (PCL) to investigate bone formation from mesenchymal stem cells (MSCs) in rat models.

This study provides initial insights into the chondrocyte behavior on the chitosan nanofibrous surface. The results may lead to future research and discover of mechanics of cell adhesion, development of cartilage and related pathologies.

\section{MATERIALS AND METHODS}

\section{Materials}

All chemicals were of analytical-grade or better. Chitosan with $81.7 \%$ of deacetylation (276 kDa, Lot \# 01-CISQ-1702) was purchased from Vanson HaloSource (Redmond, WA, USA) and was used in all experiments without further purification. Polyethylene oxide (PEO, $5000 \mathrm{kDa}$ ) was purchased from Sigma-Aldrich (St. Louis, MO, USA). Canine chondrocytes were obtained from Dr. Mark Beatty (College of Dentistry, University of Nebraska Medical School, Lincoln, NE, USA). Cell culture media and reagents were obtained from Invitrogen (Carlsbad, CA, USA).

\section{Preparation of chitosan fibrous mat by EHD methods}

To make electrospun chitosan fibers, a solution formulation of proprietary composition (Kamterter II, LLC, Lincoln, NE, USA) was used. Chitosan powder is soluble in low-molecular-weight carboxylic and mineral acids. However, conventional chitosan solution formulations display electrical conductivities that are unacceptably large for electrospinning processing. Such liquids undergo deep atomization, i.e., high charge density, they break up into polydisperse electrosprays. The Kamterter formulation makes use of innocuous additives and co-solvents, yielding a conductivity of $216 \Omega \mathrm{S} / \mathrm{cm}$, a surface tension of $31.8 \mathrm{dyne} / \mathrm{cm}$ and a viscosity of $53.7 \mathrm{cP}$ at $17.9 \%$ torque. The nominal chitosan content in the liquid is $1 \%$ by weight. To this solution, a small amount of polyethyleneoxide (PEO) was added. PEO, in small amounts, acts as a plasticizer in electrospinning processes [38]. As an example, to prepare the final chitosan solution for making electrospun fibers, $10 \mathrm{ml}$ of starting chitosan solution was mixed with $x \mathrm{ml}$ of $5 \%$ PEO $(x=0.2,0.05,0.025$, etc.).

The electrospinning setup used to make oriented fibers is shown in Fig. 1. The syringe (Hamilton, Reno, NV, USA) has a 20 gauge needle, and solutions were forced through the needle with the aid of a Cole Parmer model 74900 series syringe pump. The rotating disk collector electrode was placed at the distance $d$ between 12 and $29 \mathrm{~cm}$, and was made to rotate at an angular velocity in the range of 592$1779 \mathrm{rpm}$ by means of an electric motor. Two kinds of disks were used. The 


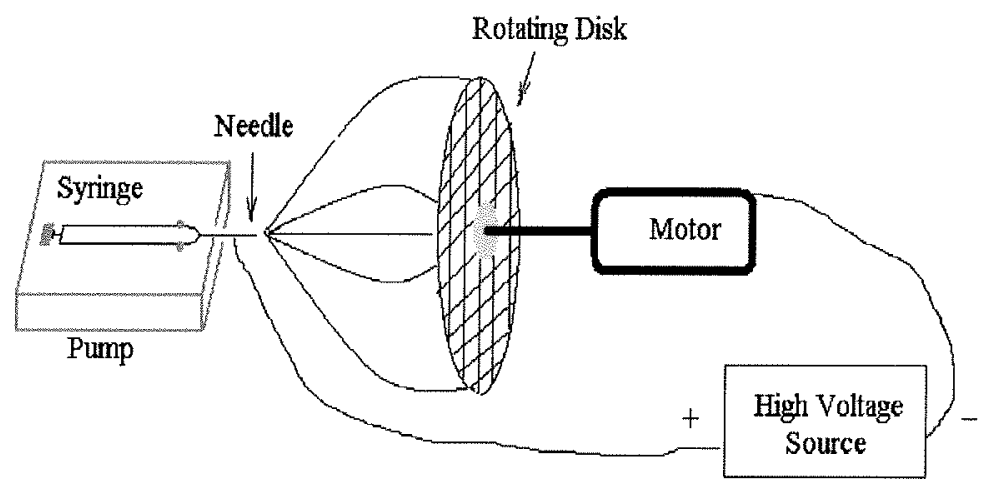

Figure 1. Electrospinning set-up. The chitosan solutions are forced through the syringe needle with the aid of a pump. The rotating disk collects nanofibers while rotating.

small one has an outside diameter of $13 \mathrm{~cm}$ and the large one has a diameter of $28 \mathrm{~cm}$. An industrial heat gun and a $500 \mathrm{~W}$ lamp were often used to facilitate solvent evaporation on fiber collection.

\section{Preparation of chitosan membrane by air-drying to serve as controls}

Chitosan (2\%) dissolved in 1\% acetic acid (Sigma) aqueous solution was cast onto glass surfaces and air-dried. The chitosan used here was the same batch of chitosan used for making electrospun mats. The dried films were neutralized with $0.1 \mathrm{M}$ $\mathrm{NaOH}$ (Sigma) aqueous solution for $30 \mathrm{~min}$ and then rinsed and submerged in deionized water for $30 \mathrm{~min}$. The films were air-dried for storage and rehydrated in phosphate-buffered saline (PBS) 1 day before use.

\section{Tensile test}

The tensile properties of the electrospun mats and cast chitosan films (controls) were measured by an Instron machine (Model 1123, Instron, Canton, MA, USA). Three dog-bone-shaped specimens (length $=3 \mathrm{~cm}$, width $=1 \mathrm{~cm}$, gauge length $=1 \mathrm{~cm}$, gauge width $=0.25 \mathrm{~cm}$ ) were cut out of the electrospun mats and cast films. The specimens were cut by using a scalpel in all direction without considering the alignment of the fiber. Consequently, the tensile strength and modulus obtained are bulk (average) values of the samples (cast films and fibrous mats). The average thickness of the electrospun chitosan fiber mat and the cast chitosan membranes (control) was $0.29 \mathrm{~mm}$ and $0.12 \mathrm{~mm}$, respectively. The samples were wetted thoroughly with DI water prior to the tests. The tests were done at room temperature with the crosshead moving at $2 \mathrm{~mm} / \mathrm{min}$. The load cell used was $50 \mathrm{kgf}$. The load (kgf)-displacement ( $\mathrm{mm}$ ) data were recorded by the computer software provided by Instron and converted into stress (MPa)-strain $(\mathrm{mm} / \mathrm{mm})$ curves to obtain ultimate tensile stress (MPa) and Young's modulus (MPa). 
The dried electrospun and cast films were coated with gold-palladium (Au-Pd) and viewed under a Scanning Electron Microscope (SEM, s-3000N, Hitachi, Tokyo, Japan).

\section{Chondrocyte cell adhesion and viability test with MTT (3-(4,5-dimethylthiazol-2-yl)-2,5-diphenyltetrazoliumbromide) assay}

Three specimens $(2 \mathrm{~cm} \times 2 \mathrm{~cm})$ of each sample were placed on the bottom of the wells of a 24-well polystyrene tissue culture plate (TCP, Falcon brand, Fisher, Pittsburgh, PA, USA) and completely covered the bottom of each well. Samples were rehydrated and disinfected with $70 \%$ ethanol aqueous solution and exposed to UV light overnight. Samples were then rinsed with sterile PBS and coated with $2 \mu \mathrm{l}$ fetal bovine serum (FBS, Gibco, Grand Island, NY, USA) before cell seeding. Canine chondrocytes were seeded onto the electrospun and cast films at $5 \times 10^{4}$ cells $/ \mathrm{cm}^{2}\left(1 \times 10^{5}\right.$ cells/well $)$. Cells were cultured in RPMI medium (Gibco) plus 10\% FBS and $1 \times$ antibiotic-antimycotic (Gibco). Cells seeded on the polystyrene surface served as controls. The 24-well TCP was kept in a cell culture incubator at $37^{\circ} \mathrm{C}, 100 \%$ humidity and $5 \% \mathrm{CO}_{2} .24 \mathrm{~h}$ later, the cell adhesion was examined by gently pipette the medium up and down to remove unattached cells into suspension and count the number of unattached cells by a hemocytometer. After $72 \mathrm{~h}$, medium from each well was removed and samples were rinsed with sterile PBS. $312 \mu \mathrm{l}$ of MTT solution ( $1 \mathrm{mg} \mathrm{MTT} / \mathrm{ml}$ phenol red free medium) was added to each well. After $4 \mathrm{~h}$, the MTT solution was removed and $625 \mu \mathrm{l}$ isopropanol was added to extract the formazan dye. The plate was placed in the incubator for $10 \mathrm{~min}$, followed by $15 \mathrm{~min}$ at room temperature. $100 \mu \mathrm{l}$ formazan-isopropanol solution was added to an ELISA plate and read at $595 \mathrm{~nm}$ by a microplate reader (Elx800, BioTek Instrument, Clarkston, MI, USA). The result is reported in percentage viability compared to the control (\% control).

\section{Chondrocyte growth kinetics}

Three specimens $(2 \mathrm{~cm} \times 2 \mathrm{~cm})$ were cut out of the electrospun and cast films and placed at the bottom of a 24-well TCP. The specimens completely covered the bottom of the well to prevent cells settling on the polystyrene surface. Samples were disinfected with $70 \%$ ethanol and kept under UV in sterile PBS overnight. Before cell seeding, samples were coated with $2 \mu \mathrm{l}$ FBS. Chondrocytes were seeded onto the samples at $5 \times 10^{4}$ cells $/ \mathrm{cm}^{2}\left(1 \times 10^{5}\right.$ cells/well $)$. Cells were fed with RPMI medium (Gibco) plus 10\% FBS and $1 \times$ antibiotic-antimycotic (Gibco), and kept in a cell-culture incubator at $37^{\circ} \mathrm{C}, 100 \%$ humidity and $5 \% \mathrm{CO}_{2}$. Cell numbers were counted after 3, 7 and 10 days. Medium was removed from each well. $300 \mu \mathrm{l}$ trypsin (Gibco) solution ( $0.25 \%$ trypsin in sterile PBS) was added to each well and we waited $30 \mathrm{~min}$ for the cells to detach. The solution was pipetted up and 
down to get cells into suspension and take the suspension for cell counting using a hemocytometer.

\section{Chondrocyte cell morphology on the samples}

Chondrocytes were seeded onto the electrospun and cast chitosan films at $1 \times$ $10^{5}$ cells $/ \mathrm{cm}^{2}$; cells on the polystyrene surface served as controls. After 3 days in culture, samples were prepared to be viewed under SEM. Briefly, samples were rinsed with PBS and cross-linked with $2.5 \%$ glutaldehyde/PBS solution for $30 \mathrm{~min}$. The glutaraldehyde was subsequently rinsed off with PBS and dehydrate the samples in serial ethanol aqueous solutions (from 20 to $100 \%$ ) for $15 \mathrm{~min}$ in each concentration. The $100 \%$ ethanol was removed with hexamethyl disilazane (HMDS, Sigma) and finally samples were air-dried. Sputter-coating of the samples with Au was carried out prior to SEM.

\section{Statistical analysis}

The numerical data from each experiment were the average from at least triplicate samples. Same experiments were repeated for three times to ensure the repeatability of the methods used. Student's $t$-test was used for statistical analysis and statistical differences were declared as $P<0.05$.

\section{RESULTS AND DISCUSSION}

We have recently shown that by making minor equipment modifications, fibers, nanoshells and nanotubes could be produced by the ES process [39, 40]. One of the reasons why ES has been historically applied to soluble organic polymers is that low-conductivity and low-surface tension liquids are required to elongate the electrified jet into strands without electrospray formation. Therefore, it is nonaqueous solutions containing the target material's precursors that typically afford electrospinning, and most dissolved inorganics are, thus, disqualified in such a scenario. Thus, it comes as no surprise that chitosan, which has long been known to be soluble only in low-molecular-weight acids, has not been electrospun until now. We expected our initial attempts to electrospin chitosan-acetic acid blends to have an extremely low probability of success, given the high conductivity and surface tension of such solutions. Indeed, electrospray-derived polydisperse chitosan nanobeads were obtained in all trials. By using a proprietary strategy that lowered the surface tension of the solution, we were able to make fibers from a $1 \%$ $(\mathrm{w} / \mathrm{v})$ solution of chitosan.

The PEO-chitosan formulation is a two-polymer homogeneous mixture. The very high molecular mass of these two components $(>100 \mathrm{kDa})$, coupled with the characteristic times of the electrospinning process, would make it physically impossible for such bulky polymers to diffuse toward segregation layers on time prior to fiber 
strand formation (jet velocity is approx. $10 \mathrm{~m} / \mathrm{s}$ ). The local entanglements between PEO and chitosan with a molecular mass above $100 \mathrm{kDa}$ in a homogeneous solution would prevent one of the two polymers to diffuse out and form a charged nano-jet predominantly based on one of the polymers.

One way to make continuous, aligned chitosan nanofibers involved replacing the collector electrode with a spinning disk rotating at $400-500 \mathrm{rpm}$. In this way, fibers were deposited in a tangential orientation relative to the disk. Figure 2 shows the high level of fiber orientation achieved by this technique. Interestingly, fibers deposited on the disk's surface were in a gel state and experienced a small level of bridging, as seen in Fig. 2. On deposition of an electrically charged fiber, it appears that a simple and rapid discharge mechanism consists of establishing such points of contact with adjacent, or sub-layer fibers. The generation of such extremely thin inter-fiber filaments simply cannot occur between two discharged, gelatinous
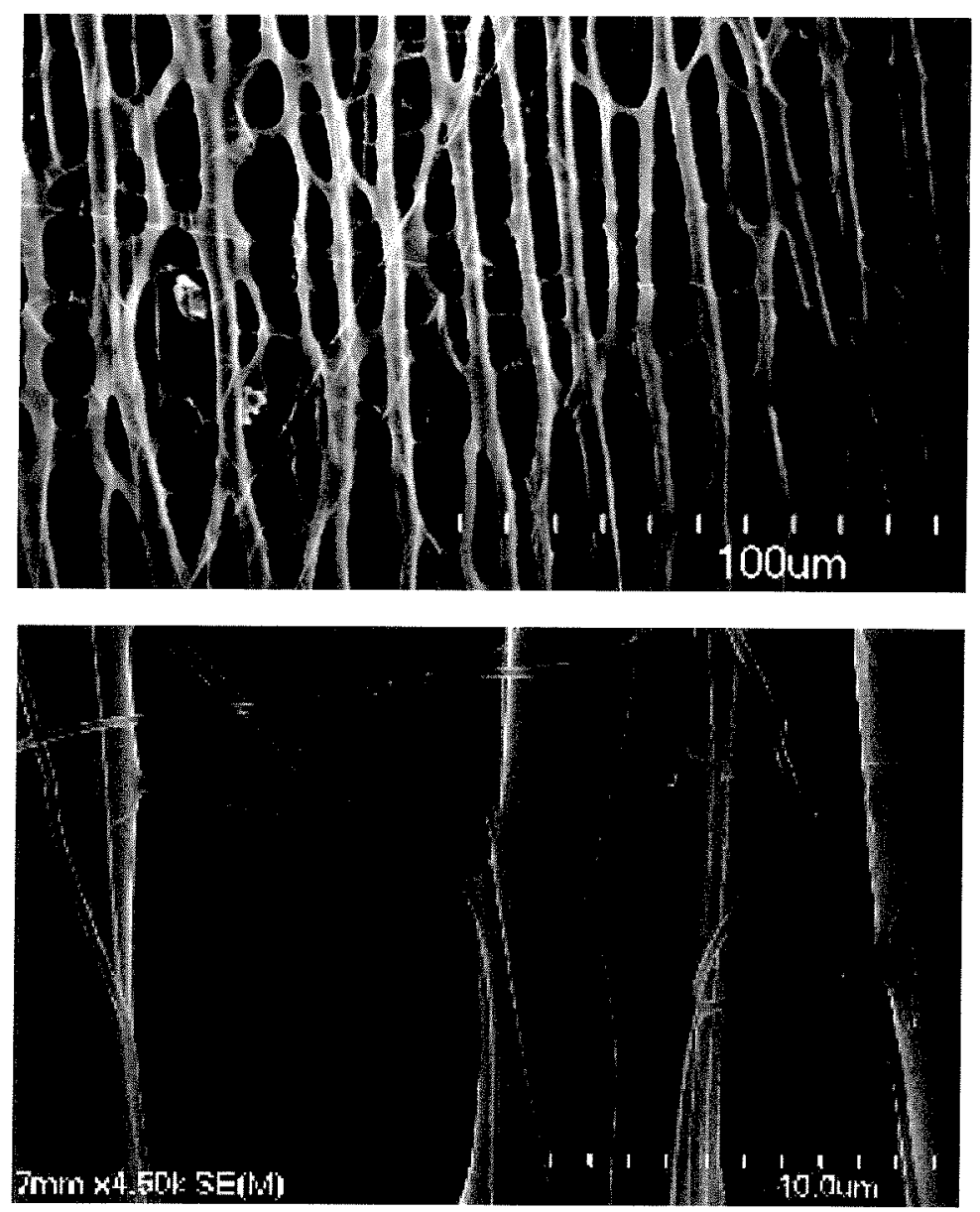

Figure 2. SEM images of the aligned fiber of the electrospun film. Fibers deposited on the surface of the disk were in a gel state and experienced a small level of bridging. 
fiber strands in light of surface tension arguments. Note that, while the 'parent' fibers in these particular experiments were approx. $3 \mu \mathrm{m}$ in diameter, the 'bridging' filaments were more than an order of magnitude thinner than the parent fibers. If this charge dissipation process is controllable, then we believe that it will be unique in that it will impart the scaffold not only an obvious resistance against tear in the direction of the fibers, but also some level of mechanical stability perpendicular to them.

\section{Tensile test}

The tensile properties of the scaffolds with aligned fiber and cast chitosan membrane are shown in Fig. 3. The data indicate that the electrospun mat has a significantly higher modulus $(2.25 \pm 0.67 \mathrm{MPa})$ compared to the cast film $(1.19 \pm 0.22 \mathrm{MPa})$. There is not a significant difference in the ultimate tensile strength between both the two samples. The ultimate tensile strength of the cast film was $0.93 \pm 0.54 \mathrm{MPa}$ and that of the electrospun sample was $0.63 \pm 0.16 \mathrm{MPa}$.

\section{Chondrocyte cell adhesion and viability test with MTT assay}

$24 \mathrm{~h}$ after cell seeding, there were no detached cells seen in the hemocytometer under the microscope. This indicates that the electrospun film provides good initial chondrocyte cell attachment. The viability of the chondrocyte cells cultured on the films after a week is shown in Fig. 4. Cells on the electrospun films showed an

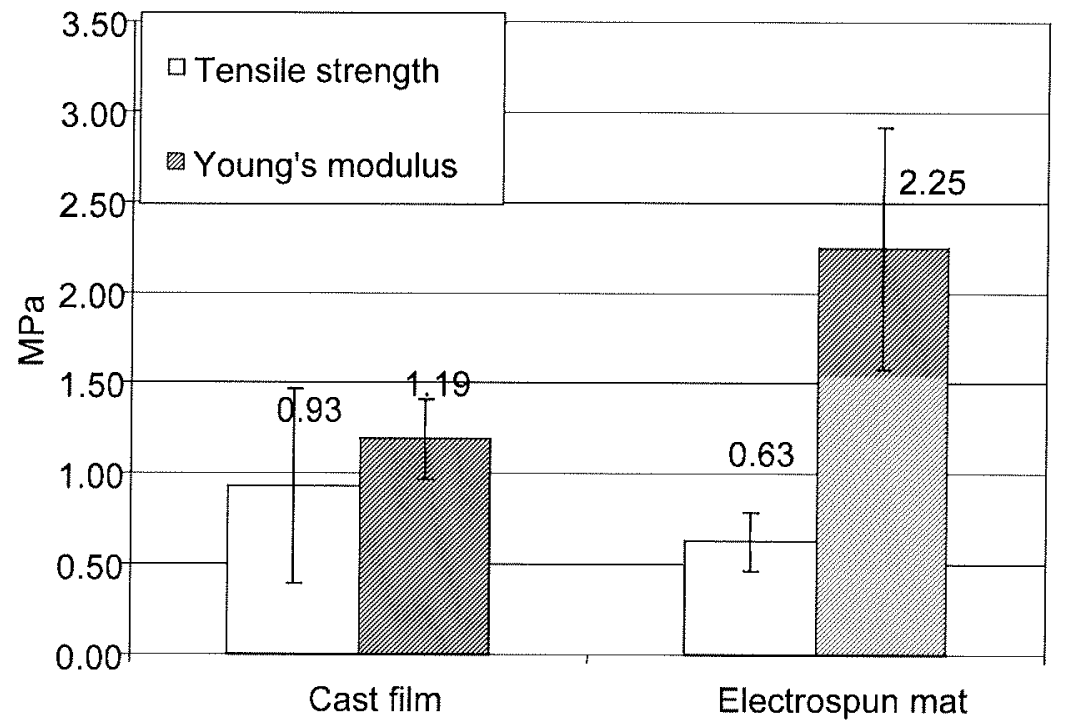

Figure 3. Ultimate tensile strength (MPa) and Young's modulus (MPa) of the electrospun and cast chitosan films. The test was done by an Instron using a $50 \mathrm{kgf}$ load cell with crosshead moving at $2 \mathrm{~mm} / \mathrm{min}$. The modulus of the electrospun film is higher $(P<0.01)$ than that of the cast films, whereas there is not a significant difference between the tensile strengths of the films. 


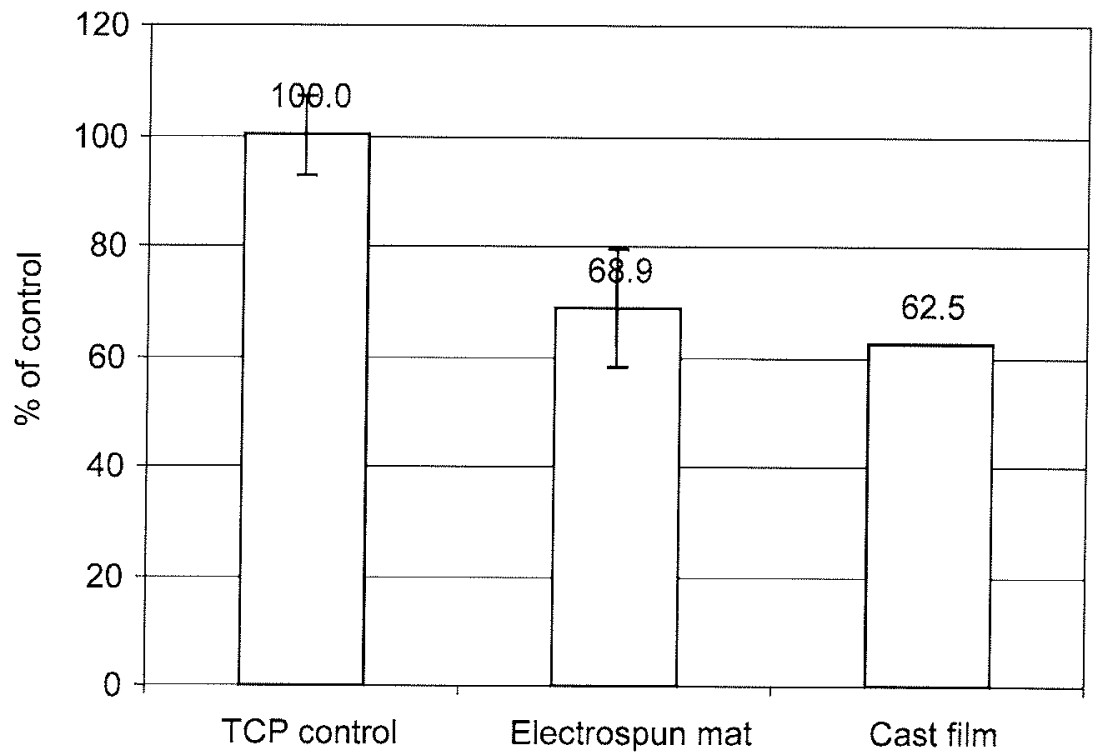

Figure 4. Chondrocyte cell viability on electrospun and cast chitosan films assayed with MTT after 7 days in culture. Cells on the electrospun and cast films had 69 and $63 \%$ viability, respectively, compared to that on the control TCP plate.

almost $70 \%$ viability compared to those on the control plate. Cells on the cast film showed a slightly lower viability (62\%) compared to the electrospun mat, although the numbers were not significantly different. This leads us to believe that the electrospinning process or reagents employed do not have an inhibitory effect of cell growth.

\section{Chondrocyte proliferation}

Figure 5 shows the chondrocyte cell growth over 10 days on both cast films and electrospun mats. Chondrocyte seeded on the electrospun films seem to grow over the culture period. The cell proliferation on the cast film seemed to provide faster cell growth in the first week than that on the electrospun films. But cell growth on the electrospun films surpassed that on cast films on day 10 . The reason could be that the cells on the cast films reached confluency before day 10 and started detaching, whereas those on the electrospun films kept on growing due to the late initial take-off. Though cells on the electrospun films did not proliferate as fast as those on the cast film in the first week, their viability was high, as can be seen from the MTT assay provided. In our future efforts we will include growth factors like TGF- $\beta 1$ and IGF- 1 or proteins like bone morphogenic proteins (BMPs), to enhance matrix biosynthesis and mitotic activity in the chondrocytes, decrease catabolism, and improve the rate of cell proliferation [41, 42].

One of the focuses of this study is to compare the cast films (without micro surface features), and the ES mat made of fibers with diameters in the sub-micron 


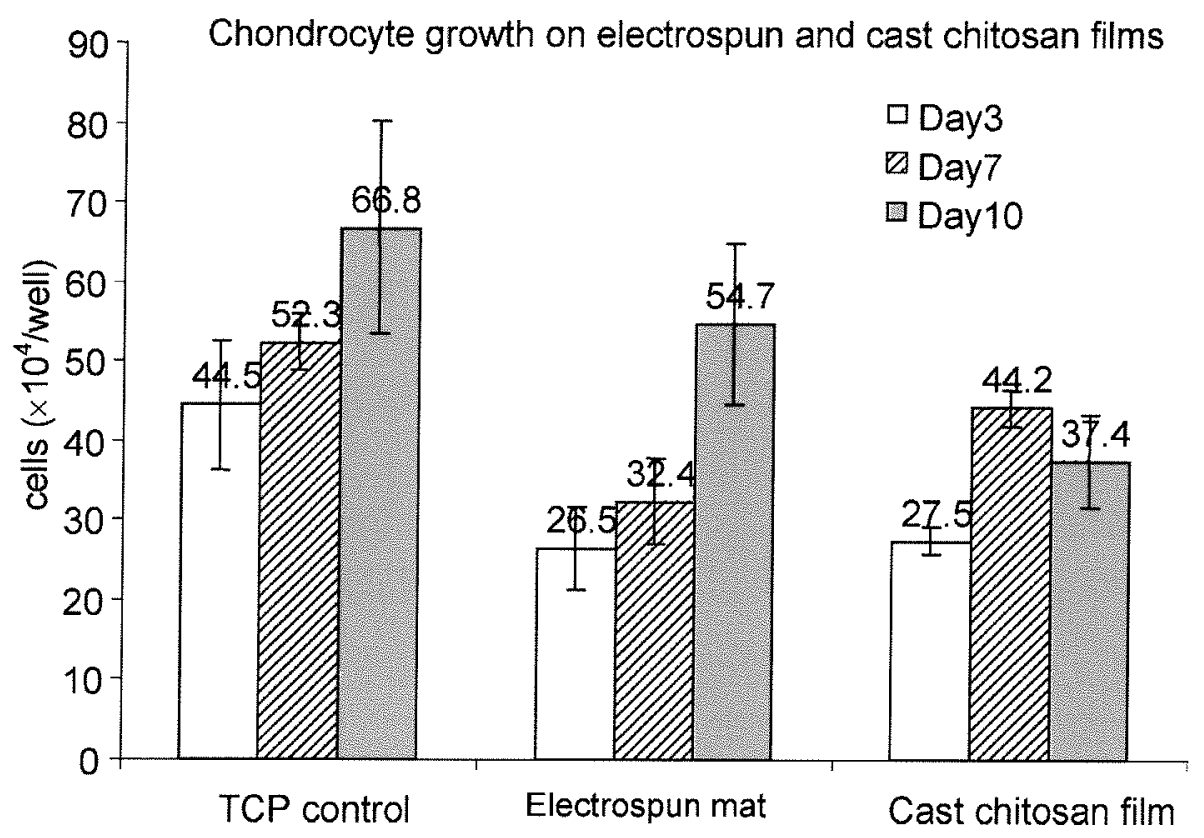

Figure 5. Chondrocyte proliferation on the electrospun and cast films after 3, 7 and 10 days in culture.

size. There are studies showing that cells proliferate better on surfaces with microfeatures $[43,44]$, which agree with the results in this study.

\section{Chondrocyte cell morphology on the samples}

The SEM images of chondrocyte cells growing on the electrospun and cast films 3 days in culture are shown in Fig. 6. The cell morphology on the films is similar to that on the control surface. The cells spread out and attached to the surface with extra cellular matrix deposited and bridging each other.

\section{CONCLUSIONS}

Chondrocyte cells growing on electrospun chitosan mats showed a good cell adhesion, proliferation profile and viability. They presented typical chondrocyte morphology and put down extracellular matrix after three days in culture on the electrospun mats. The cell tests showed the chitosan nanofiber mats have good biocompatibility.

The results also demonstrated that the chitosan nanofiber mat with fibers aligned has a higher modulus compared to anisotropic films made by solvent casting. This implies a potential application that once 3D scaffolds are made by electrospinning with fibers and pores aligned in different directions, their compression strength may vary and, thus, affect the amount of load transferred to the cells inside the scaffolds. A mechanism of controlled load distribution may, thus, be developed by controlling the fiber and pore orientation by the electrospining process. Chondrocyte phenotype expression can be optimized with varying pore sizes and loads. 


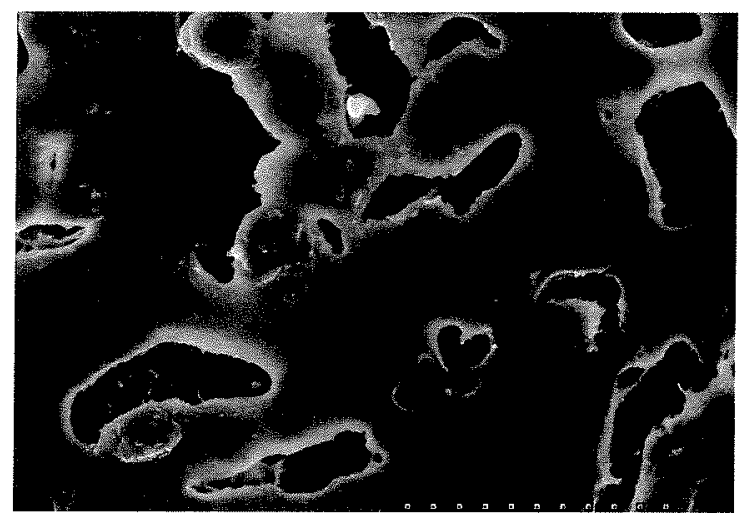

(a)

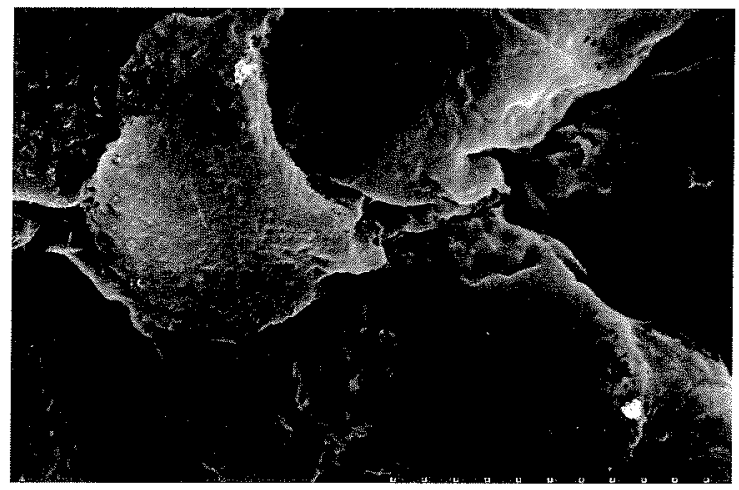

(b)

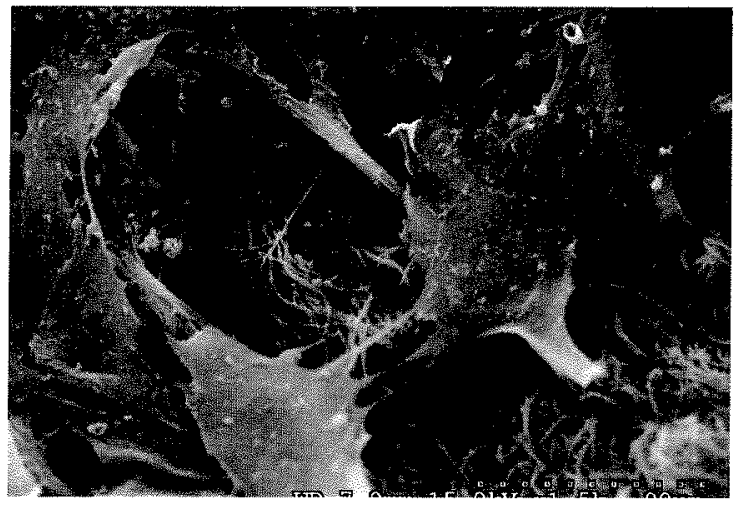

(c)

Figure 6. Chondrocytes on (a) polystyrene TCP, (b) cast chitosan film and (c) electrospun film after three days in culture. The scale bar in (a) is $50 \mu \mathrm{m}$, in (b) and (c) it is $20 \mu \mathrm{m}$. 


\section{REFERENCES}

[1]. W. T. Green, Clin. Orthoped. Relat. Res. 124, 237 (1977).

[2]. J. A. Buckwalter and H. J. Mankin, J. Bone Jt. Surg. 79A, 612 (1977).

[3]. L. Dahlberg and A. Kreicbergs, J. Orthoped. Res. 9, 11 (1991).

[4]. D. A. Hendrickson, A. J. Nixon, D. A. Grande, R. J. Todhunter, R. M.

Minor, H. Erb and G. Lust, J. Orthoped. Res. 12, 485 (1994).

[5]. S. R. Frenkel, B. Toolan, D. Menche, M. Pitman and J. M. Pachence, J. Bone Jt. Surg. 79B, 831 (1997).

[6]. L. A. Freed, J. C. Marquis, A. Nohris, J. Emmanuel, A. G. Mikos and R. Langer, J. Biomed. Mater. Res. 27, 11 (1993).

[7]. D. P. Speer, M. Chvapil, R. G. Volz and M. D. Holmes, Clin. Orthoped. Relat. Res. 144, 326 (1979).

[8]. S. Wakitani, G. Tatsuhiko, S. Pineda, G. Y. Young and V. Goldberg, J. Bone Jt. Surg. 76A, 579 (1994).

[9]. D. Robinson, N. Halperin and Z. Nevo, Calcif. Tissue Int. 46, 246 (1990). [10]. M. Sittinger, D. Reitzel, M. Dauner, C. Hammer and J. Bijja, J. Biomed. Mater. Res. 33, 57 (1996).

[11]. R. J. Minns, D. S. Muckle and J. E. Donkin, Biomaterials 3, 81 (1982).

[12]. K. Messner and J. Gilquist, Biomaterials 14, 513 (1993).

[13]. T. Minns and S. Nehrer, Orthopedics 20, 525 (1997).

[14]. E. M. Darling and K. A. Athanasiou, Ann. Biomed. Eng. 31, 1114 (2003). [15]. Z. Ma, C. Gao, Y. Gong, J. Ji and J. Shen, J. Biomed. Mater. Res. 63, 838 (2002).

[16]. J. L. van Susante, P. Buma, G. J. van Osch, D. Versleyen, P. M. van der Kraan, W. B. van der Berg and G. N. Homminga, Acta Orthoped. Scand. 66, 549 (1995).

[17]. L. Schuman, P. Buma, D. Versleyen, B. de Man, P. M. van der Kraan, W. B. van den Berg and G. N. Homminga, Biomaterials 16, 809 (1995). [18]. C. Frondoza, A. Sohrabi and D. Hungerford, Biomaterials 17, 879 (1996). 
[19]. L. B. Rocha, G. Goissis and M. A. Rossi, Biomaterials 23, 449 (2002).

[20]. S. Roche, M. C. Ronziere, D. Herbage and A. M. Freyria, Biomaterials 22, 9 (2001).

[21]. D. A. Grande, C. Halberstadt, G. Naughton, R. Schwartz and M. Ryhana, J. Biomed. Mater. Res. 34, 211 (1997).

[22]. S. H. Hsu, C. L. Tsai and C. M. Tang, Artif. Organs 26, 647 (2002).

[23]. S. J. Bryant and K. S. Anseth, J. Biomed. Mater. Res. 59, 63 (2002)

[24]. K. A. Davis and K. S. Anseth, Crit. Rev. Ther. Drug Carrier Syst. 19, 385 (2002).

[25]. H. Yoshimoto, Y. M. Shin, H. Terai and J. P. Vacanti, Biomaterials 24, 2077 (2003).

[26]. G. E. Wnek, M. E. Carr, D. G. Simpson and G. L. Bowlin, Nanolett 3, 213(2003).

[27]. F. V. Sechriest, Y. J. Miao, C. Niyibizi, H. W. T. Matthew, C. H. Evans and J. K. Suh, J. Biomed. Mater. Res. 49, 534 (2000).

[28]. E. D. Boland, G. E. Wnek, D. G. Simpson, K. J. Pawlowski and G. L. Bowlin, J. Macromol. Sci. Pure Appl. Chem. A38, 1231 (2001). [29]. W. J. Li, C. T. Laurencin, E. J. Caterson, R. S. Tuan and F. K. Ko, J. Biomed. Mater. Res. 60, 613 (2002).

[30]. B. R. Olsen, in: Principles of Tissue Engineering, R. Lanza, R. Langer andW. Chick (Eds) p. 47. Academic Press, San Diego, CA (1997).

Evaluation of electrospun chitosan fibers 873

[31]. A. Lahiji, A. Sohrabi, D. S. Hungerford and C. G. Frondoza, J. Biomed. Mater. Res. 51, 586 (2000).

[32]. J. H. Cho, S. H. Kim, K. D. Park, M. C. Jung, W. I. Yang, S. W. Han, J. Y. Noh and J. W. Lee, Biomaterials 25, 5743 (2004).

[33]. Y. Yuan, P. Zhang, Y. Yang, X. Wang and X. Gu, Biomaterials 25, 4273 (2004). 
[34]. Y. Yin, F. Ye, J. Cui, F. Zhang, X. Li and K. Yao, J. Biomed. Mater. Res. 67A, 844 (2003).

[35] A. Denuziere, D. Ferrier, O. Damour and A. Domard, Biomaterials 19, 1275 (1998).

[36]. J. A. Matthews, G. E. Wnek, D. G. Simpson and G. L. Bowlin, Biomacromolecules 3, 232 (2002).

[37]. M. Shin, H. Yoshimoto and J. Vacanti, Tissue Eng. 10, 33 (2004).

[38]. D. Li and Y. Xia, Nano Lett. 5, 933 (2004).

[39]. G. F. Larsen, R. Spertz and R. Velarde-Ortiz, Adv. Mater. 16, 166 (2004).

[40]. G. Larsen, R. Velarde-Ortiz, K. Minchow, A. Barrero and I. G. Loscertales, J. Am. Chem. Soc. 125, 1154 (2003).

[41]. H. Nochi, J. H. Sung, J. Lou, H. D. Adkisson, W. J. Maloney and K. A. Hruska, J. Bone Miner. Res. 19, 111 (2004).

[42]. M. Locker, O. Kellermann, M. Boucquey, H. Khun, M. Huerre and A. Poliard, J. Bone Miner. Res. 19, 100 (2004).

[43]. D. C. Miller, A. Thapa, K. M. Haberstroh and T. J. Webster, Biomaterials 25, 53 (2004).

[44]. T. W. Chung, D. Z. Liu, S. Y. Wang and S. S. Wang, Biomaterials 24, 4655 (2003). 